\title{
Summary
}

\section{L. CRAWFORD}

\section{Kitt Peak National Observatory and Cerro Tololo Inter-American Observatory}

Obviously we had a better than average meeting, as usually by the last hour of the last day evaporation of the audience has been severe-it's rather slight today.

It's difficult for me to summarize the meeting, since I've been impressed by some papers, encouraged by some, and confused by some! I need automation for this job, to have digitized the papers, subtracted the background noise, filtered appropriately, done all the other magic inherent in the word automation, and then outputed a summary on our display screen. Anyway, I hope the filter I've used has not destroyed the signal.

I won't attempt to describe or summarize the papers in detail-that was for the authors. Also, if you haven't gotten it already, you won't get it in these few minutes.

There are many new telescopes, but not nearly enough ; therefore we need high efficiency of operation. For these telescopes we will have very elaborate instruments: scanners, image tubes, and so forth. There are or will be many photographic plates, and other collected information requiring high efficiency in measurement. There will be lots of "raw" data produced; hence we need highly efficient data reduction techniques. These are the general subject areas of the papers, though, of course, many of the papers overlap several areas. There were 39 papers, and I have divided them into the subject areas as follows:

$\begin{array}{lr}\text { Automation of telescopes, } & 10 ; \\ \text { Automation of instruments, } & 9 ; \\ \text { Automation of plate measuring, } & 12 ; \\ \text { Automation of data processing, } & 6 ; \\ \text { and miscellaneous, } & 2 .\end{array}$

There were two major things I missed:

1. One (or 4) invited review papers, to tie it all together, to cover topics omitted by the contributed papers, and to set the stage for the contributed papers.

2. Input to us optical astronomers (by a review paper?) of the knowledge of automation gained by radio astronomers and nuclear physicists.

The meeting was excellent, however, for exchanging information of what people have been doing or planning to do, and the reasons why. I'm sure the contacts made here will prove very fruitful in the days to come.

This is an important role of Commission 9: to promote, as here, the exchange of technical information and ideas, thereby amplifying progress (I hope the feedback is positive!) and achieving standardization where possible.

It was especially good to have the meeting here in Edinburgh where so much has already been attempted and accomplished in the way of automation. They will admit, I'm sure, as we do at KPNO, that the use of "automation" grows on you. The magic that Dr. Rösch mentioned on the first day is irresistible to some people. Those who get used to working with these new techniques don't revert to older techniques. The advantage of the new techniques to them in scientific output is too great.

The situation is rather like the early use of digital computers. Few of us use logs now. Note though that the slide rule, and the brain, still have their uses!

I'm impressed that the systems, when well specified and implemented, work very well with very little trouble. The big trouble is in coping with (and editing) the output.

One other serious problem was mentioned-automation eliminates the girls. Fortunately, some observatories have kept them on, if only for display - and I'm sure there are other uses as well!

Let me restate some things from the introductory paper about the advantages of automation: 


\section{Automation}

Frees us from tiresome hack work, as did the digital computer (automation does the work, not the thinking);

Increases accuracy;

Increases speed;

Achieves versatility.

There are many things we do now that we would never have done manually. Automation also allows us to take the data in such a way and in such a volume as to allow very sophisticated data analysis.

2. Automation allows us in some cases to break through technical thresholds in our pursuit of new knowledge.

With all these new techniques, it is very hard to separate automation from instrumentation, from the reduction process, and from man's direct involvement, as many papers here showed. They also showed:

1. that the costs can be great, and therefore we must plan carefully just how we spend the hard-toget money;

2. that we are not now idea limited, but are money and manpower limited;

3. that the problems involved are great, but that the rewards are also great;

4. that the jargon is formidable;

5. that with the use of small computers we can replace many hardwired boxes if

(a) we do it with care, so as not to make it even harder to achieve versatility in scientific effort ;

(b) we can afford it.

(I note that during the last few years when I've been involved in the large telescope projects, I have been able to keep my astronomy alive by an automatic observing process. I give the observing programs to a good assistant who returns later with the data. I don't even have to go to the computer center, and the total cost is less than $\$ 10000 / \mathrm{yr}$. The assistant gets her name on the paper too!)

A few further remarks extracted from the papers:

(a) A warning to those who are planning automation from those who are in over their heads with it: "Since a computer can do anything, we wanted it to do everything. It didn't."

(b) To industry: We astronomers are very glad that you're interested in our problems. We are too! We hope you always keep your interest in research tools as well as in your money making ventures!

(c) That many different approaches and many different computer systems work well. It's the love they get and the astronomical drive to use them that are the keys to success. 